\title{
A performance based approach for the seismic assessment and rehabilitation of existing $\mathrm{RC}$ buildings
}

\author{
Paolo Negro' ${ }^{1}$ Elena Mola ${ }^{2}$
}

Received: 25 February 2015/Accepted: 17 November 2015/Published online: 28 November 2015

(C) The Author(s) 2015. This article is published with open access at Springerlink.com

\begin{abstract}
Using the results of a past experimental project in which a non-ductile, seismically under-designed building was tested pseudo dynamically in its as-built configuration as well as in two conceptually different rehabilitated configurations, a method for a simplified seismic performance assessment, based on the standard Pacific Earthquake Engineering Research Centre (PEER) methodology, is discussed. The two retrofitting methods compared in the experimental activity were: Fiber Reinforced Polymer wrapping of all the vertical elements and r.c. jacketing of selected vertical elements. The experimental activity consisted in bi-directional pseudodynamic (PsD) tests at increasing Peak Ground Acceleration (PGA) levels on a full-scale specimen in the two configurations. For this specific study, the results of the tests were used to quantify the achieved improvements in terms of performance brought about by the two retrofitting strategies in the tested building. In order to do that, at first, the benchmark structure was converted into a real building of the same age, then the costs for rehabilitation and repair and the losses referred to the 'realistic' building were estimated with the advice of an Italian licensed practicing engineer, based on market values and current practice. Finally, the performance-based assessment exercise consisted into the evaluation of the costs associated to each rehabilitation measure and the expected losses during the remaining life-span of the building for all the defined limit states: these numbers represent a suitable performance indicator for a simple and straightforward comparison of the different retrofitting strategies.
\end{abstract}

Keywords Testing - Performance-based design - Assessment - Rehabilitation · Irregularity $\cdot$ FRP

Paolo Negro

paolo.negro@jrc.ec.europa.eu

Elena Mola

elena.mola@ecsd.it

1 European Commission, Joint Research Centre (JRC), Institute for the Protection and Security of the Citizen (IPSC), European Laboratory for Structural Assessment (ELSA), Ispra, Italy

2 ECSD S.r.l. Engineering, Milan, Italy 


\section{Introduction}

The issue of seismic vulnerability assessment and rehabilitation of underperforming existing buildings is a very important and complex problem, especially in seismic-prone areas such as the southern European Countries. Current codified procedures for the assessment of such structures include a number of analysis options, ranging from linear response spectrum to more refined pushover analyses, which are not always familiar to the practicing engineer. A vulnerability assessment study, especially if the structure exhibits some peculiar features, such as in-plan- or in-height irregularity, older rebar arrangements and outdated structural detailing, unusual materials, such as low strength concrete and smooth rebar, can thus yield very scattered results, depending on the type of analysis and the basic modeling assumptions adopted by the engineer.

The same holds true for the design of a retrofitting intervention: a wide range of options is available to the practitioner, but no codified approach can provide prescriptive guidelines that fit any and every case, because an effective retrofitting strategy needs to take into account a number of factors, such as the main structural issues highlighted in the vulnerability analysis, budget constraints, feasibility issues, owner's requirements and a number of other boundary conditions.

In recent years, an extensive research activity has been carried out in order to investigate the response of existing buildings and to derive some general concepts to guide practitioners tackling the complex issue of seismic retrofitting (see a review in Oliveto and Marletta 2005): worldwide used guidelines, such as FEMA 273 (BSSC 1997a), FEMA 274 (BSSC 1997b) and FEMA 356 (BSSC 2000) can be cited as examples.

In particular, in the framework of the research activity of the ELSA Laboratory of the Joint Research Centre, pseudo-dynamic testing of a real-size plan-wise irregular 3-storey frame structure, both in the as-built and in two retrofitted configurations, was carried out as the core of the research project SPEAR (Seismic PErformance Assessment and Rehabilitation of existing buildings). The experimental activity carried out on the SPEAR structure allowed a one-of-a-kind wealth of data to be collected and previously published (Fardis and Negro 2005; Mola and Negro 2006; Mola 2007).

In the pre-test phase, a blind vulnerability assessment study was carried out, using different software and analysis options, so that the scatter of the results could be gauged and the effectiveness of the different modelling assumptions in providing a reliable estimate of the experimental response could be assessed by comparison with the test results.

Once in the post-test phase, it became clear that a good understanding of the complex features of the response of the specimen was difficult to be obtained, due to the effects of double eccentricities, adding up to poor structural detailing and lack of ductility.

The two retrofitting interventions that were then conceived for the specimen were: a ductility-oriented FRP wrapping intervention and a strength-enhancing RC jacketing intervention, aimed at tackling the main structural issues highlighted by the numerical analysis and by the test results, i.e. lack of global and local ductility and remarkable torsional effects negatively affecting the seismic response. The results of this activity, and of the related tests, were published in Negro and Mola (2007), Di Ludovico et al. (2008), with particular reference to the FRP retrofitting intervention in the latter.

At the end of the experimental activity, a more practitioner-oriented performance-based assessment exercise was also carried out, in order to assess the effectiveness of both strategies in an objective, performance-oriented way, in an attempt to partially generalise the results of the research and convey their meaning in a more immediate way. The 
performance-based assessment exercise, reported in the present paper, included the estimations of the costs of the different damage states, provided by the engineering practice. The probability of attaining each damage state was obtained by combining the experimental skeleton curves with the probabilistic definition of the expected intensities and conclusions were finally drawn on the effectiveness of the retrofitting interventions in terms of reduction of the expected loss during the lifetime of the building. The approach proved to be at the same time accurate and simple enough in the case at hand; moreover, since the comparisons are ultimately made in budgetary terms, it allowed a final costbenefit evaluation for each different proposed intervention.

\section{The spear experimental activity}

The SPEAR structure is a simplification of an actual three-storey building representative of construction practice of the "60s and '70s in southern European Countries, without specific provisions for earthquake resistance. A thorough description of the aims and the experimental and numerical activity of the SPEAR project is given elsewhere (Negro et al. 2004; Molina et al. 2004).

The structure is regular in elevation: it is a three-storey building with a storey height of $3 \mathrm{~m}$. The plan configuration is non symmetric in two directions (Fig. 1a), with 2-bay frames spanning from 3 to 6 metres; the presence of a balcony on one side and of two offsets increases the plan irregularity, shifting the centre of stiffness away from the centre of mass.

Eight out of the nine columns have a square 250 by $250 \mathrm{~mm}$ cross-section; the ninth one, column C6 in Fig. 1, has a cross-section of 250 by $750 \mathrm{~mm}$, which makes it much stiffer and stronger than the others along the $\mathrm{Y}$ direction, as defined in the same figure, which is the strong direction for the whole structure.

The centre of stiffness (CR) (based on column secant-to-yield stiffness) is eccentric with respect to the mass centre $(\mathrm{CM})$ by $1.3 \mathrm{~m}$ in the $\mathrm{X}$ direction ( $\sim 13 \%$ of plan dimension) and by $1.0 \mathrm{~m}$ in the $\mathrm{Y}$ direction $(\sim 9.5 \%)$.

Smooth rebar is used for all the structural members and the rebar arrangement in the joints, completely lacking confinement (no stirrups, either from the beams or the columns, are present in the joints) does not allow any dissipative failure mechanism to develop in the
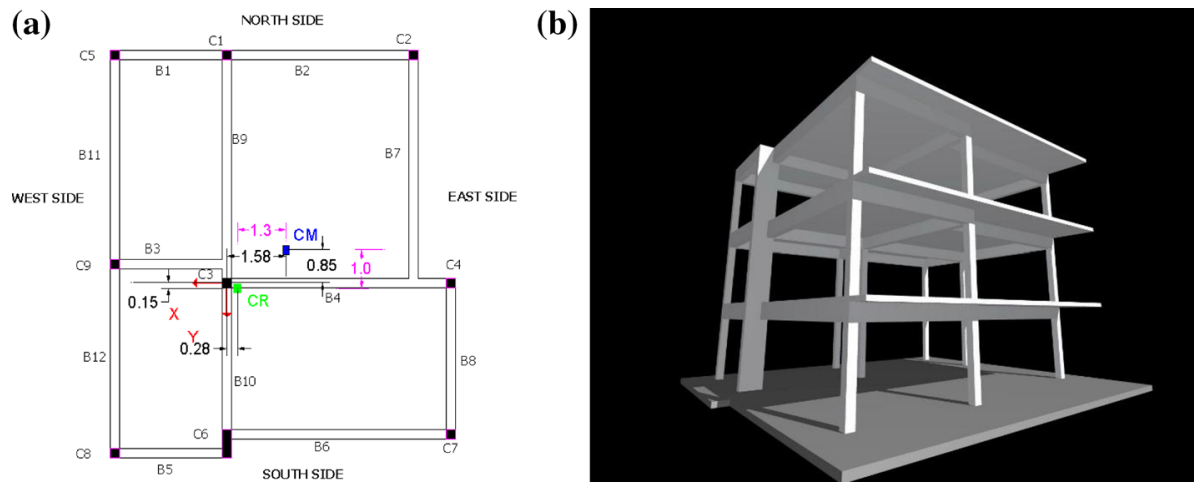

Fig. 1 The SPEAR structure, a plan configuration, b rendering 
frames under earthquake excitation. As a consequence, the building is not designed for ductility, which is further affected by the less efficient bonding mechanism between smooth rebar and concrete with respect to that developing in corrugated rebar.

Moreover, as per common practice in the past, part of the longitudinal rebar was bent at the ends of the beams: this practice has been abandoned in more recent years because the most effective rebar arrangement for shear strength and confinement is that including only stirrups. The lack of proper shear reinforcement in vertical elements as well strongly affects the global ductility of the system: in particular, column C6, whose behavior is closer to that of a shear wall, is the most critical one under this respect.

In Fig. 2a-c, some of the design drawings are shown, in which some of the abovedescribed structural features can be observed.

Given the bi-eccentricity of the specimen, a bi-directional PsD test had to be carried out, with the application of both components (longitudinal and transverse) of the chosen input accelerogram; three degrees of freedom (DoFs) per storey were thus taken into account: two translations and one rotation along the vertical axis.

Two different retrofitting techniques were applied to the specimen, which were aimed at tackling the most blatant structural issues: the first one consisted in increasing the ductility supply of the vertical elements and of selected joints by means of Fiber Reinforced Polymer (FRP) wrapping. This rehabilitation strategy, as mentioned above, was aimed at tackling only the most obvious structural weakness of the building, i.e. ductility, while at the same time leaving global strength and stiffness untouched. Glass fiber wraps were used, with unidirectional fiber orientation for the columns and quadriaxial fiber orientation for the joints and the strong column C6, expected to exhibit significant shear damage. For all the details regarding the design of this intervention, see Di Ludovico et al. (2008).

(a)

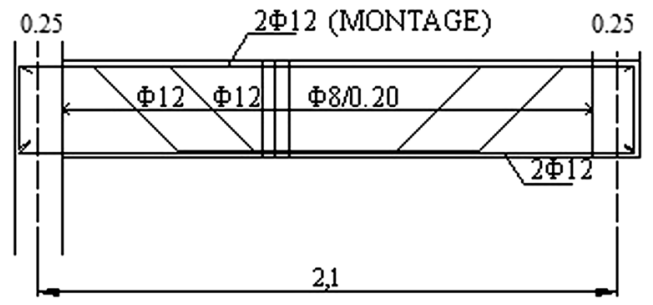

(b)

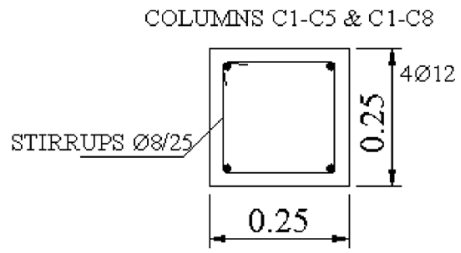

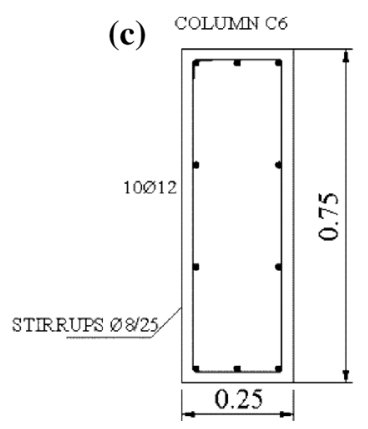

Fig. 2 Reinforcement details of the SPEAR structure, a beam, b column, c column-wall 
After removing the FRP wrapping, the second retrofitting intervention was carried out, consisting of RC-jacketing of selected vertical elements (columns $\mathrm{C} 1$ and $\mathrm{C} 4$ in Fig. 1, along their whole height), with the aim of enhancing the global capacity and reducing torsional effects in the seismic response. Details of the r.c. jacketing intervention are shown in Fig. 3.

In the present case, since the focus was on increasing capacity rather than stiffness, a very thin layer of concrete was added, covering a large amount of additional longitudinal corrugated steel rebars.

Three rounds of tests were thus carried out: the first one on the structure in the as-built configuration, the second one in the FRP-retrofitted configuration and the third one in the RC-jacketed configuration. The accelerograms used as input were the Montenegro'79 Herceg-Novi records for the longitudinal and transverse component, artificially modified to fit to the EC8 spectrum, scaled to different levels of PGA: 0.15 and $0.20 \mathrm{~g}$ for the original structure, 0.20 and $0.30 \mathrm{~g}$ for the specimen in the two retrofitted configurations, and applied to the structure according to the combination of direction and orientation that would maximize torsional effects, based on a number of pre-test numerical simulations. Moreover, a preliminary test at low PGA level $(0.02 \mathrm{~g})$, carried out in each of the three configurations, allowed the first mode shapes of the structure, along with its initial frequencies and modal damping values to be estimated (Molina et al. 1999).
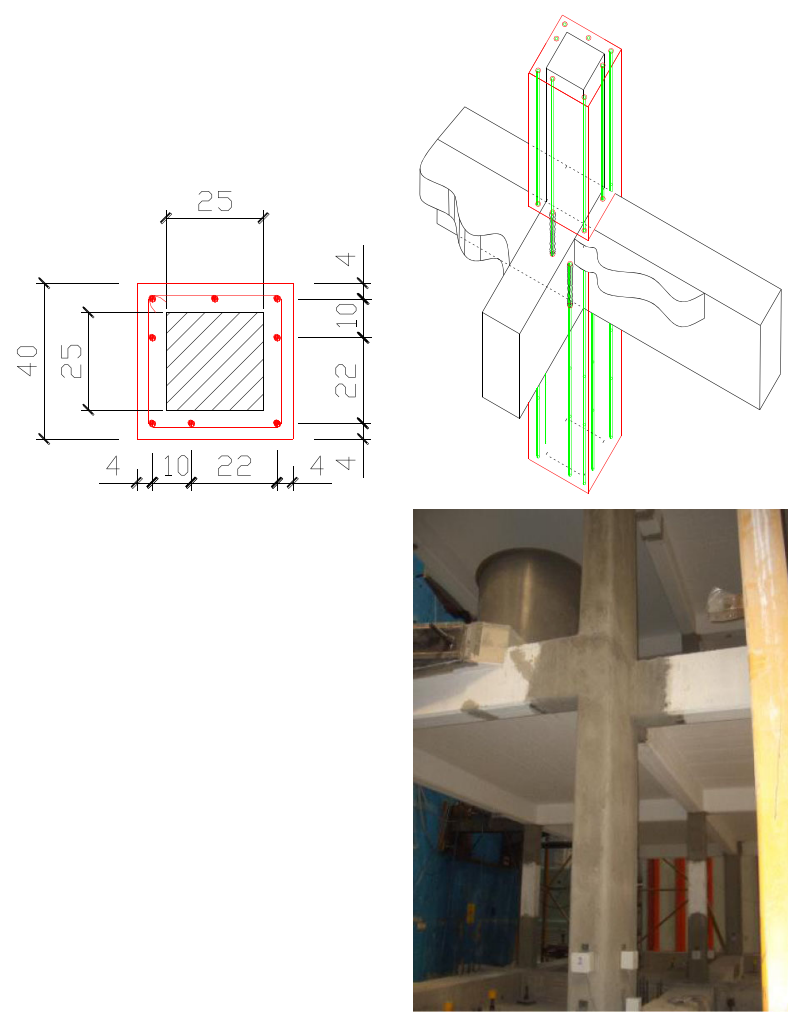
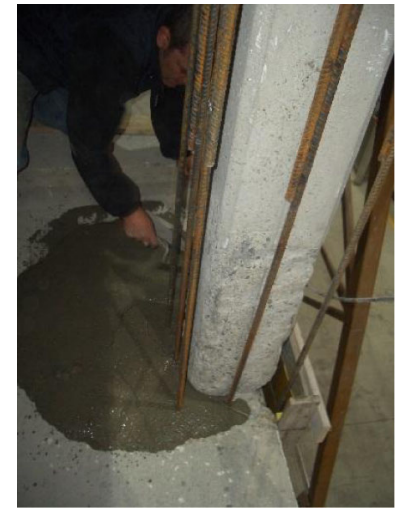

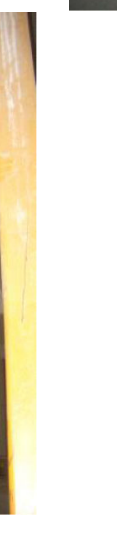

Fig. 3 Details of the r.c. strengthening intervention 
Global quantities, such as displacement and rotation at the $\mathrm{CM}$ at each floor, base shear, storey shears, storey drifts, absorbed energy at each floor and for each degree of freedom, were measured. Local instrumentation was also set at the top and bottom of a number of columns and beams, in the most meaningful locations.

In the following, only the results of the $0.20 \mathrm{~g}$ PGA intensity test will be briefly discussed for the original structure. Both the results of the 0.20 PGA test and of the 0.30 PGA test will be addressed for the FRP and r.c. retrofitted specimen with a focus only on the data needed for the subsequent assessment exercise. For more detailed presentations of all the experimental results see Fardis and Negro (2005), Mola and Negro (2006), Mola (2007).

\section{The spear experimental activity: highlights of the results}

\subsection{Original structure}

In the PsD tests in the as-built configuration, as expected, torsional effects affected the response, in an often unpredictable way: a comparison between the drift measured at the $\mathrm{CM}$ and the drifts of the edge columns, the most deformed ones, clearly showed that the effects of torsion on the drifts of the edge columns were remarkable in both directions. The drifts were computed from the experimental data.

When interpreting the data, the apparent failure mechanism exhibited by the specimen was of the soft-storey kind but at the second floor and not at the first one, since the maximum measured drifts were located at the second storey. Due to the higher axial load of first storey columns, which negatively affects the ductility capacity of their cross sections, the weak storey was expected to be the first: this fact had also been highlighted by the numerical analyses carried out before the test (Fardis and Negro 2005). In the present case, the effects of higher modes and the dynamic amplification of eccentricity were the most likely cause of this behavior.

Finally, it became quite obvious that the almost total lack of ductility of the vertical elements (due to the poor structural detailing design) was a key factor in leading the building to failure. Some pictures of the specimen after the test at $0.20 \mathrm{~g}$ PGA intensity, Fig. 4, can help clarify the level and location of the damage. At this intensity, extensive spalling of the cover was visible at the top of the columns (especially C3 which is the one with an axial load ratio about 1.5 times higher than the others), light spalling and flexural cracking took place at the top of corner columns, due to torsional effects). Since the specimen needed to remain repairable for further testing, no further tests at increased PGA levels were carried out.
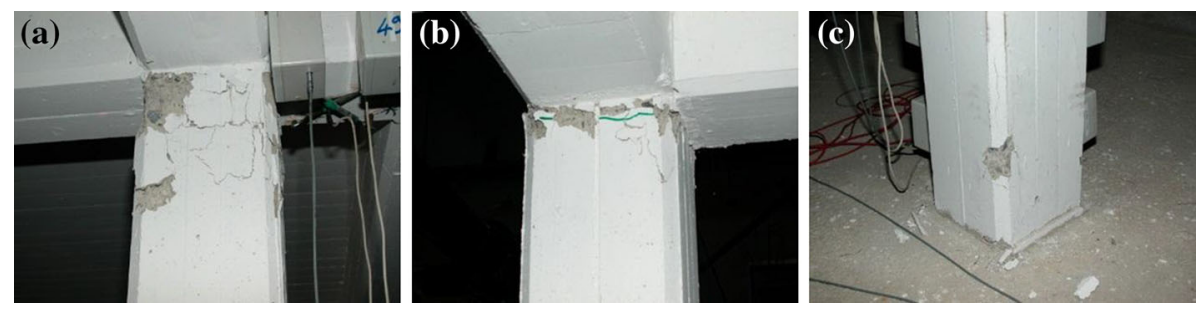

Fig. 4 Visible damage in the specimen after the 0.20 PGA test: a extensive spalling at the top of columns (C3); b light spalling and flexural cracking at the top of corner columns (C1); c base of column C3 
The somehow unexpected behavior of the as-built specimen made it clear that the vulnerability assessment of existing buildings, even when apparently simple, is never straightforward and easy, as discussed above, and that, for this reason, the choice of the correct retrofitting strategy is not easy either.

Through the subsequent tests, carried out on the same specimen after each of the two interventions, FRP wrapping first, then selective r.c. jacketing, the goal then became gauging the effectiveness of each of the two basic approaches in the most objective possible way. In the following, a short review of the main results of the tests on the retrofitted specimen is provided.

\subsection{FRP-wrapped specimen}

For the sake of comparison, in Fig. 5, the global hysteresis loops for the original and FRP retrofitted structure in the X (Fig. 5a) and Y (Fig. 5b) direction and $\theta$ rotation (Fig. 5c) are reported. The plots show the increased ductility and the practically unchanged global stiffness. The increased ductility in the $\mathrm{X}$ direction is much larger than in the $\mathrm{Y}$ direction and $\theta$ rotation.

\subsection{RC-jacketed structure}

In this case, the relative importance of the rotational DoF with respect to the translational ones in the energy dissipation process decreased; the attained maximum rotations were also reduced.

The initial slope of the loops increased, as the retrofitting intervention modified the global structural stiffness, affecting in particular the $\mathrm{X}$ direction, which was originally

(a)

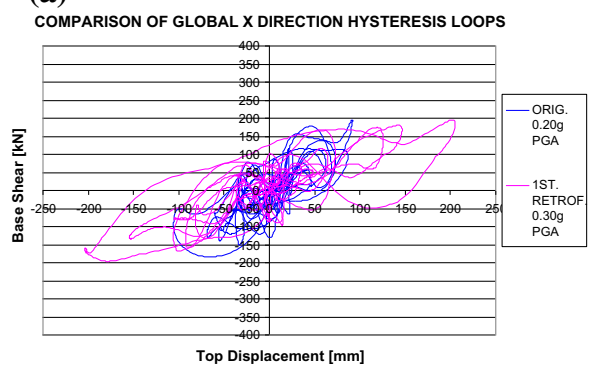

(b)

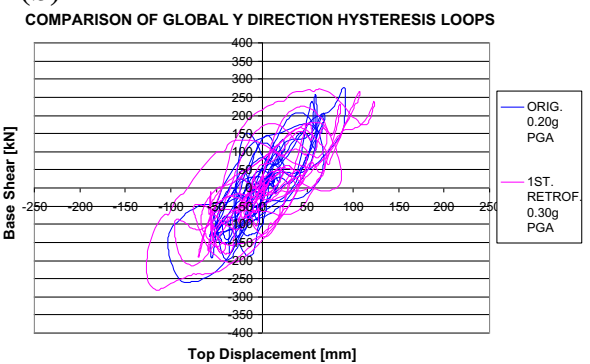

(c) COMPARISON OF GLOBAL TETA ROTATION HYSTERESIS

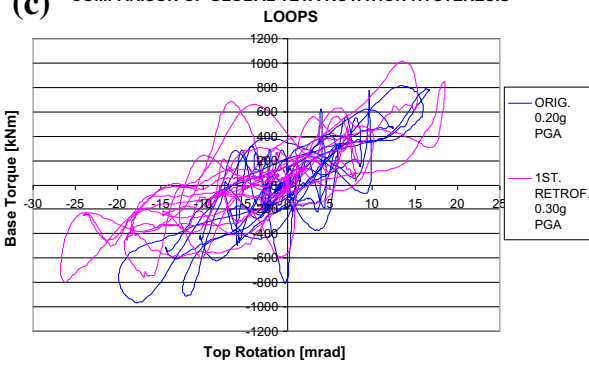

Fig. 5 Comparison of the behavior of the original and FRP strengthened buildings: a X direction, $\mathbf{b} \mathrm{Y}$ direction, $\mathbf{c} \theta$ rotation 
significantly weaker than the $\mathrm{Y}$ direction, thus being more sensitive to the increase in the cross-section of the two retrofitted vertical elements.

The damage developed by the specimen at the $0.20 \mathrm{~g}$ PGA level of excitation was more intense in comparison with that developed by the structure in the FRP-wrapped configuration. In the r.c. retrofitted specimen, damage of the vertical elements was fairly visible, mainly at the top of second and first storey columns. The damage pattern was thus very similar to that developed by the as-built structure, mainly concentrated on the elements with the highest axial load ratio, with heavy spalling of concrete cover and initiation of buckling of vertical rebars.

In Fig. 6, the global hysteresis loops for the original and R.C. jacketed structure in the $\mathrm{X}$ (Fig. 6a) and Y (Fig. 6b) direction and $\theta$ rotation (Fig. 6c)are reported. The plots show the slightly increased global stiffness and the reduced importance of the global rotational DOF in the dissipative mechanism.

\subsection{Discussion of the experimental results}

The original structure was tested at differing levels of peak ground acceleration $(0.02,0.15$ and $0.2 \mathrm{~g}$ ), attaining a severe level of damage for $0.2 \mathrm{~g}$. The test sequence was not continued any further, to allow for repair, rehabilitation and further testing; however, due to the intrinsic lack of ductility of the structure, one might realistically assume that $0.2 \mathrm{~g}$ is close to the ultimate peak ground acceleration capacity.

The rehabilitation approach aimed at increasing global ductility by means of the application of FRP wrapping in all the potential plastic hinge zones proved to be

(a)

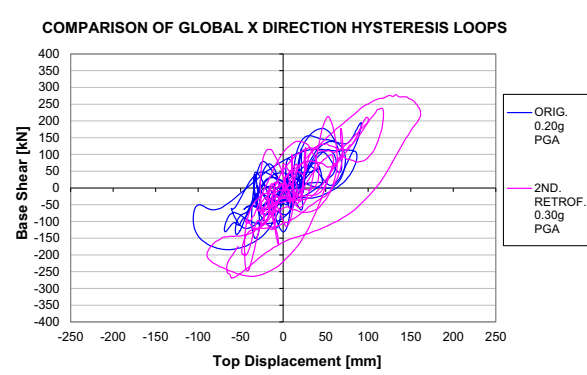

(b)

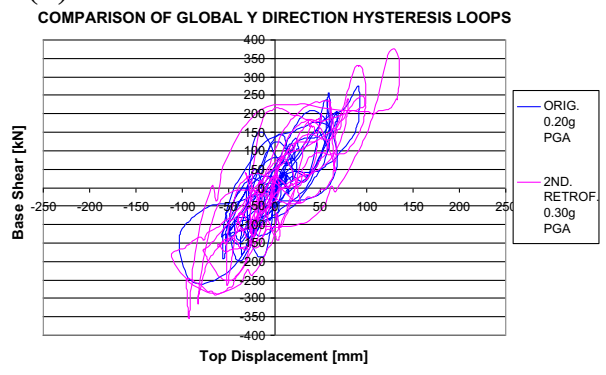

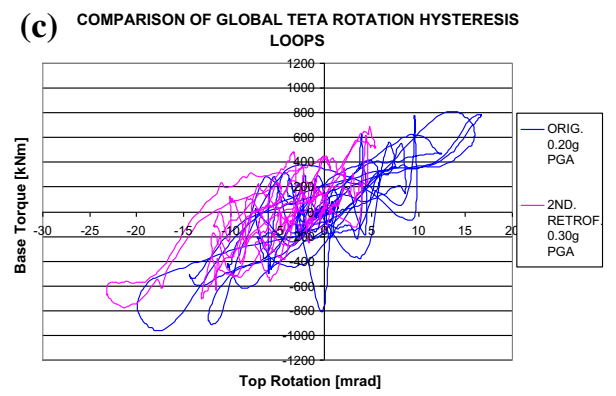

Fig. 6 Comparison of the behavior of the original and column jacketed buildings: a X direction, $\mathbf{b} \mathrm{Y}$ direction, $\mathbf{c} \theta$ rotation 
particularly effective. The FRP-wrapped structure, in fact, survived the $0.2 \mathrm{~g}$ earthquake without visible damage, and the same held true for the test with $0.3 \mathrm{~g}$, as discussed in detail in Di Ludovico et al. (2008).

The maximum drifts in the r.c. retrofitted structure turned out to be significantly reduced as compared to the original structure.

In spite of the reduction in the maximum interstorey drift, though, the r.c. structure was severely damaged at the end of the $0.2 \mathrm{~g}$ test.

In Figs. 7, 8 and 9, a comparison between the interstorey drifts and rotations at each storey and for each configuration are plotted: it can thus be noted that the FRP-retrofitted structure easily achieved much larger values of interstorey drift than both the original and the R.C. jacketed one, but the effect of the plan-irregularity, causing the drifts of the second storey to be larger than the others (as can be seen in Figs. 7b, 8b, 9b) is not mended by the intervention. On the contrary, the distribution of interstorey drifts becomes more regular in the R.C. jacketed specimen and the torsional effects are reduced (as can be seen in Fig. 9), but the maximum achievable interstorey drift is significantly lower with respect to the one achieved by the FRP-retrofitted specimen $(110 \mathrm{vs} 65 \mathrm{~mm}$, both at the second storey). In comparison with the original structure, the r.c. retrofitted one shows increased stiffness with the exception of the plots for the first floor. This is most likely caused by residual damage from the previous tests. The capacity of the r.c. retrofitted structure is higher because the $0.2 \mathrm{~g}$ PGA level excitation was attained without failure.

The conclusion which can be drawn from the experimental results is that an FRP rehabilitation approach confining all potential plastic hinge zones can significantly extend the maximum PGA which can be sustained by the building, whereas the r.c. strengthening intervention was more effective in reducing the damage corresponding to lower PGA values, but did not significantly extend the capacity, being the latter ultimately limited by the insufficient global ductility.

(a)

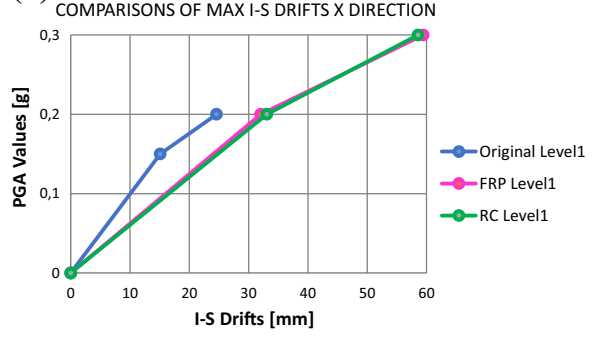

(b)

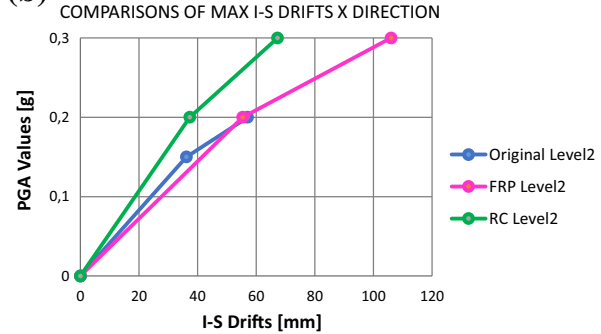

(c) COMPARISONS OF MAX I-S DRIFTS X DIRECTION

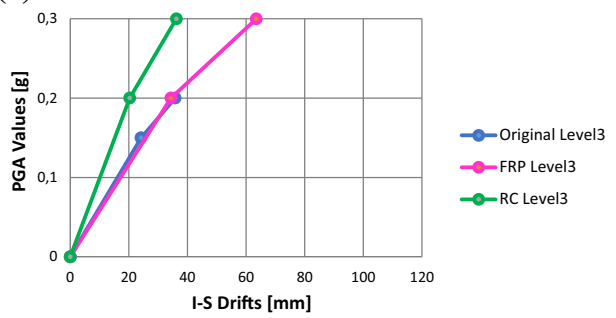

Fig. 7 Comparison of maximum interstorey drifts in the $\mathrm{X}$ direction, a 1st storey, b 2nd storey, $\mathbf{c}$ 3rd storey 
(a)

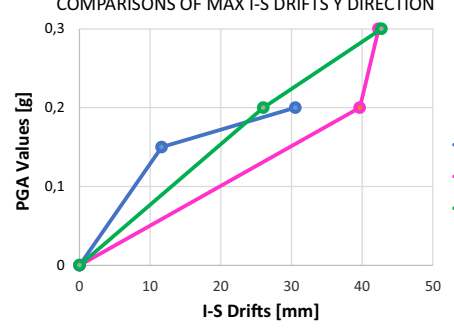

(b)

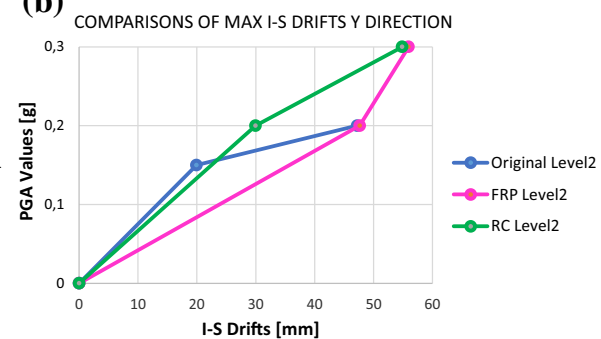

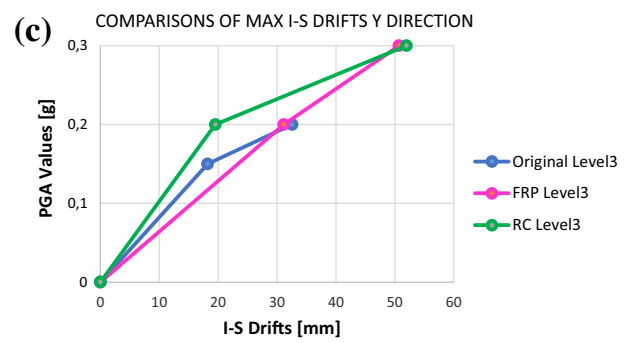

Fig. 8 Comparison of maximum interstorey drifts in the $\mathrm{Y}$ direction, a 1st storey, b 2nd storey, $\mathbf{c} 3$ rd storey

(a)

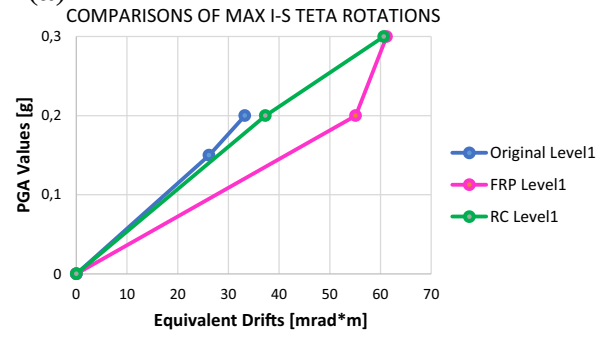

(b)

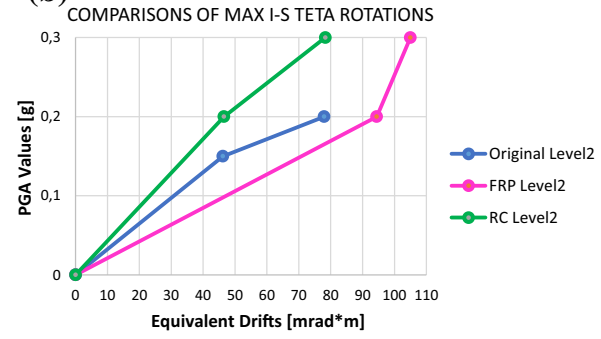

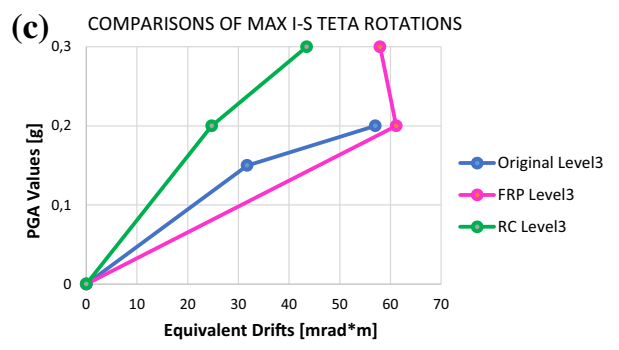

Fig. 9 Comparison of maximum interstorey rotations $\theta$, a 1st storey, b 2nd storey, $\mathbf{c} 3$ rd storey

\section{Performance-based assessment exercise}

As mentioned above, the wealth of results provided by the experimental activity, even after a thorough interpretation phase, was not sufficient to quantify the improvement with respect to the original structure, nor to decide which rehabilitation strategy was better 
performing by means of a global, easily comparable, indicator. As a consequence, a practical performance assessment method, based on the well know PEER methodology, was applied to try and derive this indicator.

The benchmark structure was converted into a real building of the same age (Fig. 10). The building was intended as an office building, had a continuous glass façade and light internal partitions (these choices were dictated by the fact that no infills were present in the frames during the tests). The costs for rehabilitation and repair and the losses computed in the following refer to the 'realistic' building conceived for this specific assessment exercise. In order to provide correct estimates of said costs, an Italian licensed practicing engineer provided advice, based on market values and current practice.

The performance-based assessment consisted into the evaluation of the costs associated to each rehabilitation measure and the expected losses during the remaining life-span of the building for all the defined limit states.

In the evaluation of the costs of the rehabilitation measures and of the repair/replacement actions needed after each damage state, both the cost of the technical intervention and the costs associated to the limitation in use of the building were considered.

An assumption, affecting the cost estimates, was made: the floor system was of the floating type (i.e., easily dismountable and re-mountable), and partitions and ceilings were amenable to easy access to the structure.

(a)

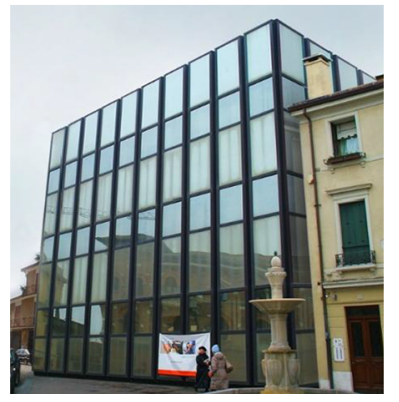

(b)

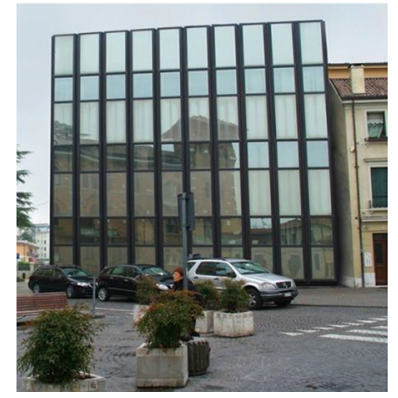

(c)

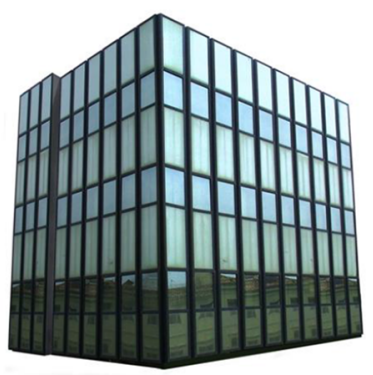

Fig. 10 Rendering of the 'realistic' SPEAR building, a close-up of the building in an urban context, b full view of the building in an urban context, c close-up of the facade

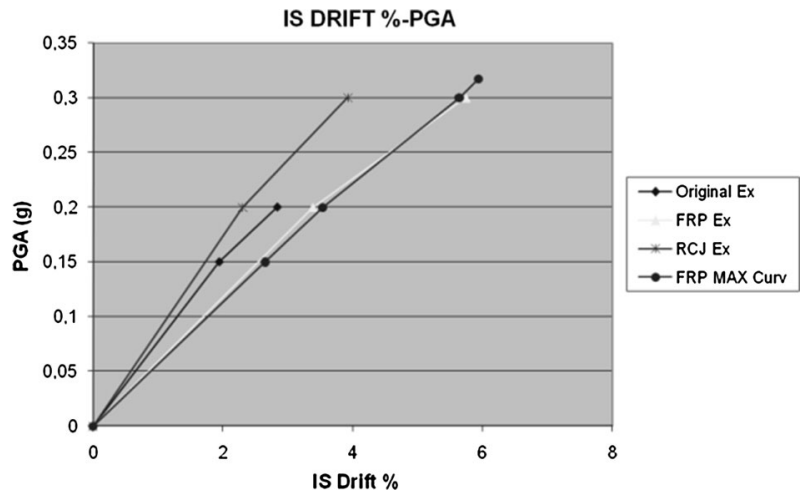

Fig. 11 Experimentally derived skeleton curves for the three configurations 
The expected life-span for the building was assumed as 20: given the age of the building and its ordinary importance, it was felt that providing an additional service life of 20 years would strike a sensible balance between costs and benefits, rather than guaranteeing an additional 50 years' service life.

The seismicity was defined with reference to a particular location in northern Italy at the border from Veneto and Friuli regions (ID N. 10083 in the recent map of seismicity of Italy, (DM 14-01-2008), corresponding to a peak ground acceleration of $0.25 \mathrm{~g}$ for a 475 years return period). The map provides a set of values of the peak ground acceleration for a discrete set of return periods, along with an interpolation formula, so that the peak ground acceleration can be obtained for any return period.

The skeleton curves providing the peak ground acceleration versus maximum interstorey drift in each configuration were obtained from the experimental results and are reported in Fig.11. From the interstorey drift thresholds defined for each limit state, the peak ground acceleration was obtained. By means of the seismic map, the peak ground acceleration values were converted into return periods and then into probability of exceedance.

Summing up the contribution of each defined limit state the total expected loss was obtained, so that a comparison of the two rehabilitation techniques could be done in terms of reduction of the total expected loss with respect to the original structure.

\subsection{Evaluation of costs}

The costs associated to each rehabilitation measures were evaluated with reference to the real building and occupancy.

FRP-wrapping would require 70,000 EUR for the placement of the laminates, 6000 EUR for dismounting, remounting and painting, plus 32,000 EUR for day-off costs. The costs for disruption of use include: moving the contents of the offices forth and back, providing new services and publicity, loss of productivity, renting of a similar building for the time required, estimated in 3 weeks for the very intervention, but affecting the office activity for 4 months. This is due to the fact that the FRP wrapping intervention is extensive, so the whole building will be affected. The total estimated cost of the intervention is therefore about 108,000 EUR.

RC-jacketing will take place with no disruption, or with limited disruption of the office activity. In fact, in this case, it is worth reminding that only a selected number of elements will be jacketed: in particular, only two columns were chosen, column $\mathrm{C} 1$ and column $\mathrm{C} 4$ in Fig. 1, to undergo concrete jacketing, which was mainly aimed at strongly increasing the rebar, with a relatively small increase in the column section dimensions.

The two columns' cross sections were increased from the original $25 \times 25 \mathrm{~cm}$ to the jacketed $40 \times 40 \mathrm{~cm}$. New rebar was added: $816 \mathrm{~mm}$ diameter bars per column were added as longitudinal reinforcement, plus new $8 \mathrm{~mm}$ diameter stirrups were added, with $10 \mathrm{~cm}$ spacing at the top and bottom of the columns at each storey (the first $70 \mathrm{~cm}$ from the slab) and $15 \mathrm{~cm}$ spacing for the remaining length of the columns, as reported in (Fardis and Negro 2005). The very cost of the intervention as specified above was quantified in 10,000 EUR. The day-off cost was estimated by assuming that the activity in the building would not be discontinued; however, a small new office would still have to be rented. The intervention will last 9 weeks and will affect the activity for 3 months. The total day-off cost is then 30,000, summing up to a total cost of 40,000 EUR.

A number of limit states were defined, and the associated costs were computed. 
The first limit state was defined as low-damage, i.e., damage to the glass façade and partitions. This was estimated as a percentage of the cost of the façade (180,000 EUR), in 36,000 EUR.

The second limit state was defined as heavy damage/loss of the façade, whose associated cost was 180,000 EUR.

The third limit state was defined as severe structural damage and, due to the intrinsic fragility of the structure in any configuration, was taken as coincident to the fourth limit state to be considered, i.e. loss-of-the building/collapse. The corresponding cost is the demolition-reconstruction cost, 570,000 EUR. The estimate of the day-off costs was computed on the basis of a 16 months period as 90,000 EUR, summing up to 660,000 EUR.

The engineering measure defining damage was selected as the maximum interstorey drift at the most affected columns (this to account for the torsional response, also considering that the most affected storey turned out to be the second rather than the first). The drift thresholds defining low-damage and heavy damage/loss of the façade were provided by the producer of the façade system as 1 and $2 \%$ respectively.

\subsection{Evaluation of the probabilities of exceedance}

The PGA values corresponding to the drifts, including the drift at failure, were obtained from the skeleton curves obtained from the tests (Fig. 9), and were treated deterministically. It has to be recalled that the ultimate values for the FRP-wrapped structure was obtained by extrapolating the monotonic curve as explained before. Also, it has to be noted that the initial branch of the skeleton curve for the FRP-wrapped structure is softer than the one of the original structure, which can only be explained by the damage suffered throughout the test sequence. For consistency, it was decided to bring the skeleton curve for the FRP-wrapped structure up to a PGA of $0.2 \mathrm{~g}$ coincident with the one of the original structure. The curve for the r.c. retrofitted structure was not modified because the intervention provided additional stiffness to the structure: the removal of the spalled cover and additional layer of concrete with corrugated rebar repaired the damage previously developed in the jacketed columns. Residual damage was thus limited. The corresponding values are given in Table 1.

The following step was to compute the probability of exceedance for the so obtained PGA values. The new Italian seismic map provides the PGA values for a discrete set of return periods, starting from a return period of 30 years. It also provides a formula for interpolating those values; moreover, the user is advised that the formula is valid only for return periods larger than 30 years, which is the case at hand. The interpolation formula provided is thus applied:

Table 1 Summary of PGA and drift values for 4 limit states in the three configurations

\begin{tabular}{|c|c|c|c|c|c|c|}
\hline \multirow[t]{2}{*}{ Limit state } & \multicolumn{2}{|c|}{ Original structure } & \multicolumn{2}{|c|}{ FRP-wrapped } & \multicolumn{2}{|c|}{ RC-jacketed } \\
\hline & Drift $(\%)$ & PGA (g) & Drift $(\%)$ & PGA (g) & Drift $(\%)$ & PGA $(g)$ \\
\hline 1 & 1 & 0.0773 & 1 & 0.0773 & 1 & 0.0870 \\
\hline 2 & 2 & 0.1533 & 2 & 0.1533 & 2 & 0.1739 \\
\hline $3 / 4$ & 3.54 & 0.2 & 5.94 & 0.3173 & 2.29 & 0.2 \\
\hline
\end{tabular}




$$
\log \left(\mathrm{a}_{\mathrm{g}}\right)=\log \left(\mathrm{a}_{\mathrm{g} 1}\right)+\log \left(\frac{\mathrm{a}_{\mathrm{g} 2}}{\mathrm{a}_{\mathrm{g} 1}}\right) \times \log \left(\frac{T_{\mathrm{R}}}{T_{\mathrm{R} 1}}\right) \times\left[\log \left(\frac{T_{\mathrm{R} 2}}{T_{\mathrm{R} 1}}\right)\right]
$$

where $\mathrm{a}_{\mathrm{g}}$ is the generic PGA value for which the corresponding return period $T_{\mathrm{R}}$ must be computed and $\mathrm{a}_{\mathrm{gi}}$ and $T_{\mathrm{Ri}}$ are the two closest tabulated values of the parameters. By solving the formula for $T_{\mathrm{R}}$, with the previously determined $\mathrm{a}_{\mathrm{g}}$ values, the corresponding return periods were determined. The probability of exceedance in $N$ years $R_{N}$ was then obtained from the formula:

$$
R_{\mathrm{N}}=1-\left(1-\frac{1}{T_{\mathrm{R}}}\right)^{\mathrm{N}}
$$

in which $\mathrm{N}$ was set to the expected lifespan of the structure, i.e., 20 years.

The probabilities of exceedance in 20 years could therefore be computed and are shown in Table 2.

\subsection{Evaluation of total expected loss}

Having computed the costs $C_{\mathrm{i}}$ associated to the attainment of each limit state, and the associated probability of exceedance $R_{20 \mathrm{i}}$, one can compute the total expected loss $L$ in each configuration by direct application of the total probability theorem as:

$$
L=\sum_{i} C_{i}\left(R_{20 i}-R_{20 i+1}\right)
$$

The total loss expected in 20 years is given in Table 3 .

In the present assessment exercise, in terms of reduction of total expected loss, the FRPwrapped solution turns out to be by far the most effective, since the total expected loss is reduced to one fourth of the one of the original structure.

On the other hand, the advantage in terms of reduction of the deformability due to torsional response which was offered by the RC-jacketed structure is not reflected in the corresponding total expected loss, which is reduced by a mere $15 \%$ with respect to the

\begin{tabular}{|c|c|c|c|c|c|c|}
\hline \multirow{2}{*}{ Limit state } & \multicolumn{2}{|c|}{ Original structure } & \multicolumn{2}{|c|}{ FRP-wrapped } & \multicolumn{2}{|c|}{ RC-jacketed } \\
\hline & $\mathrm{T}_{\mathrm{R}}$ (years) & $R_{20}(\%)$ & $\mathrm{T}_{\mathrm{R}}$ (years) & $R_{20}(\%)$ & $\mathrm{T}_{\mathrm{R}}$ (years) & $R_{20}(\%)$ \\
\hline 1 & 40.72 & 39.18 & 40.72 & 39.18 & 49.26 & 33.65 \\
\hline 2 & 151.84 & 12.38 & 151.84 & 12.38 & 199.23 & 9.573 \\
\hline $3 / 4$ & 276.20 & 6.997 & 851.52 & 2.406 & 276.20 & 6.997 \\
\hline
\end{tabular}
original structure.

Table 2 Return periods and probabilities of exceedance for the four limit states in the three configurations

Table 3 Total expected losses and investments in 20 years for the three configurations

\begin{tabular}{lccc}
\hline & Original structure & FRP-wrapped & RC-jacketed \\
\hline Total loss (EUR) & 40,263 & 9990 & 34,211 \\
Investment (EUR) & 0 & 107,500 & 39,500 \\
\hline
\end{tabular}


In terms of return of investment, it has to be noticed that none of the rehabilitation strategies has economic justification. However, it has to be recalled that neither possible casualties were accounted for in the analysis, nor the risk of loss of the contents was considered. These issues, if properly accounted for, might change the last conclusion.

It must also be recalled that the same comparative assessment of the two rehabilitation strategies, if conducted for larger eccentricities, might yield different conclusions. The same must be noted in case the extent of the r.c. jacketing intervention was larger.

\section{Conclusions}

The issue of vulnerability assessment of underperforming structures is a challenging one. Existing models do not allow a quantitative evaluation of the expected improvement to be achieved by means of standard retrofitting interventions. For this reason, the expected improvement corresponding to different methods and techniques cannot be easily evaluated. This is true up to the point that even the availability of dedicated experimental results is not sufficient to provide definitive conclusions on the matter.

Therefore, the results of the past experimental activity carried out in the framework of the SPEAR project were used as a benchmark in order to carry out a simplified assessment procedure based on the direct application of the total probability theorem to try and quantify the improvement of the performance brought about by two conceptually different retrofitting strategies. The costs associated to each rehabilitation measure were assessed according to engineering practice, including the consequences of the occupancy limitations. With the same approach, the losses corresponding to the attainment of a number of damage limit states were computed. The maximum interstorey drift was assumed as the damage measure, and was related to the peak ground acceleration in a deterministic way by using the experimentally obtained skeleton curves. The values of the peak ground acceleration were converted into return periods by using the most recent Italian seismic map, and those were converted into probabilities of exceedance. Finally, by summing the contributions of all the limit states, to total expected loss over the assumed remaining lifespan.

The reduction of the total expected loss with respect to the original structure was taken as the most important performance indicator, within the limitations of the exercise.

It can be concluded that the rehabilitation measure aimed at increasing the global available ductility performed better in reducing the expected losses. The rehabilitation measure aimed at reducing the torsional response was successful in cutting the losses associated to the lower limit states but was not as effective as the one aimed at increasing the global available ductility. This conclusion should be restricted to the case at hand (small torsional eccentricity), and might be different for more irregular structures.

The measure to increase the ductility proved to be efficient with reference to the ultimate limit state, whereas the reduction of the eccentricity was effective for the lower limit states. It might therefore be concluded, even if no direct confirmation is available, that combining the two approaches would optimize the performance.

In terms of cost-benefit analysis, none of the rehabilitation measures proved to be economically justifiable. However, different conclusions could be reached if casualties would be taken into account, or even if the probability of the loss of the contents would be considered. 
Acknowledgements The Project SPEAR was funded by the European Commission under the "Competitive and Sustainable Growth" Programme, Contract N. G6RD-2001-00525. Access to the experimental facility took place by means of the EC contract ECOLEADER N. HPRI-1999-00059. The professional expertise and valuable cooperation of all the partner institutions that took part in the different phases of the project are gratefully acknowledged. Repair and rehabilitation of the structure were carried out by MAPEI S.p.A., Milan. The pseudodynamic testing was a joint effort of the ELSA staff: the authors wish to thank all the ELSA staff for their competence and expertise.

\section{Compliance with ethical standards}

Ethical statement The authors declare that the research activity presented in the present paper did not involve human participants and/or Animals.

Conflict of interest The authors declare that hat they have no conflict of interest.

Open Access This article is distributed under the terms of the Creative Commons Attribution 4.0 International License (http://creativecommons.org/licenses/by/4.0/), which permits unrestricted use, distribution, and reproduction in any medium, provided you give appropriate credit to the original author(s) and the source, provide a link to the Creative Commons license, and indicate if changes were made.

\section{References}

BSSC (1997a) FEMA 273: NEHRP guidelines for the seismic rehabilitation of buildings. Building Seismic Safety Council, Washington, D.C

BSSC (1997b) FEMA 274: NEHRP commentary on the guidelines for the seismic rehabilitation of buildings. Building Seismic Safety Council, Washington, D.C

BSSC (2000) FEMA 356: pre-standard and commentary for the seismic rehabilitation of buildings. Building Seismic Safety Council, Washington, D.C

Di Ludovico M, Manfredi G, Mola E, Negro P, Prota A (2008) Seismic behavior of a full-scale RC structure retrofitted using GFRP laminates. J Struct Eng ASCE 134(5):810-821

DM 14/01/08, Norme Tecniche per le Costruzioni. Ministero delle infrastrutture. Gazzetta Ufficiale n.29 04/02/2008 (in Italian)

Fardis M, Negro P (ed) (2005) SPEAR (Seismic Performance Assessment and Rehabilitation): Proceedings of the International Workshop. EU Publications Office

Mola E (2007) Criteria for the seismic vulnerability reduction of existing irregular reinforced concrete structures. PhD Thesis, École Doctorale Mécanique Conception Géomécanique Matériaux, INPG Grenoble

Mola E, Negro P (2006) Post-test analysis and interpretation of the results of PsD testing on a full-size threestorey RC plan-wise irregular frame structure: new perspectives. In: Proc. of the 1st European Conference on Earthquake Engineering and Seismology, Geneva

Molina FJ, Pegon P, Verzeletti G (1999) Time domain identification from seismic pseudodynamic test results on civil engineering specimens. In: Proc. Of the 2 nd Intl. Conf. on Identification in engineering systems

Molina FJ, Buchet PH, Magonette GE, Hubert O, Negro P (2004) Bidirectional pseudodynamic technique for testing a three-storey reinforced concrete building. In: Proc. of 13th World Conference on Earthquake Engineering, Paper N. 75, Vancouver, Canada

Negro P, Mola E (2007) The importance of plan-wise irregularity. International Workshop on Measures for the Prevention of Total Collapse of Existing Low-Rise Structures, Istanbul, Turkey. Proceeding Book (2009) published as: 'Seismic risk assessment and retrofitting: with special emphasis on existing lowrise structures. Book Series: Geotechnical Geological and Earthquake Engineering, Vol.10, Edited by: Ilki, A., Karadogan, F., Pala, S. et al

Negro P, Mola E, Molina FJ, Magonette G (2004) Full-Scale PsD Testing Of A Torsionally Unbalanced Three-Storey Non-Seismic RC Frame. In: Proc. of 13th World Conference on Earthquake Engineering, Paper N. 968, Vancouver, Canada

Oliveto G, Marletta M (2005) Seismic retrofitting of reinforced concrete buildings using traditional and innovative techniques. ISET J Earthq Technol 42(2-3):21-46 